\title{
Avaliação higiênico-sanitária do comércio de peixes antes, durante e após a semana santa no estado do Ceará
}

\author{
Hygienic-sanitary evaluation of fish trade before, during and after holy week in the state of \\ Ceará
Evaluación higiénico-sanitaria del comercio pesquero antes, durante y despúes de la semana santa por la provincia de Ceará

\begin{abstract}
Sâmia Killville da Cruz Abreu Teixeira ${ }^{1}$, Samille Kilvia da Cruz Abreu', Brend Loma Vasconcelos Carneiro ${ }^{1}$, Iara Lílian da Rocha Marques ${ }^{1}$, Iana Loiola Melo ${ }^{1}$, Gisvani Lopes de Vasconcelos ${ }^{1}$, Mauro Vinicius Dutra Girão ${ }^{1 *}$.
\end{abstract}

\section{RESUMO}

Objetivo: Verificar as condições higiênico-sanitárias da comercialização de peixes em mercados públicos antes, durante e após o período da Semana Santa em mercados públicos do estado do Ceará. Métodos: Foi realizado estudo investigativo, longitudinal, observacional, através da análise visual por meio de um checklist, baseado em normas do Ministério da Saúde. A coleta de dados ocorreu mensalmente em mercados públicos de quatro municípios do estado Ceará, durante três meses consecutivos. Resultados: As observações evidenciam elevado índice de inconformidades antes, durante e após o período. Dentre os fatores de risco de contaminação encontram-se falhas na higienização de utensílios, nas práticas de higiene dos manipuladores além da presença de vetores mecânicos contaminantes. Conclusão: A comercialização de peixes em mercados públicos indica condições que oferecem riscos de contaminação ao pescado, podendo não ser seguros à saúde do consumidor. Tais achados podem apresentar as autoridades sanitárias do estado do Ceará um panorama da realidade da comercialização de pescado tanto em datas comemorativas quanto ao longo do ano e, assim, estimular a realização de capacitações com os gestores e comerciantes, bem como a reestruturação higiênico-sanitária dos mercados públicos visando à segurança alimentar da população.

Palavras-chave: Carne, Comercialização de produtos, Higiene dos alimentos.

\begin{abstract}
Objective: Verify the hygienic-sanitary conditions of its commercialization in public markets before, during and after the period of Holy Week in public markets in the state of Ceará. Methods: An investigative, longitudinal, observational study was conducted through visual analysis based on checklist, based on Ministry of Health rules. Data collection took place monthly in public markets in four municipalities of the state of Ceará, for three months. Results: The observations show a high rate of nonconformities before, during and after the period. Among the contamination risk factors are faults in the hygiene of utensils, in the hygiene practices of the handlers and the presence of contaminating mechanical vectors. Conclusion: The commercialization of fish in public markets indicates conditions that offer risks of contamination to the fish, and may not be safe to the consumer's health. These findings may present the health authorities of the state of Ceara with an overview of the reality of the commercialization of fish both on commemorative dates and throughout the year, thus stimulating training with managers and traders, as well as hygienic-sanitary restructuring a public markets for the food security of the population.
\end{abstract}

Keywords: Meat, Products commerce, Food hygiene.

${ }^{1}$ Centro Universitário Inta (UNINTA), Sobal - CE. *E-mail: viniciusgirao@gmail.com 


\section{RESUMEN}

Objetivo: Verificar las condiciones higiénico-sanitarias de la comercialización del pescado en los mercados públicos antes, durante y después del período de la Semana Santa en los mercados públicos de la provincia de Ceará. Métodos: Se realizó un estudio de investigación, longitudinal, observacional, mediante análisis visual mediante un checklist, con base en estándares del Ministerio de Salud, la recolección de datos se realizó mensualmente en los mercados públicos de cuatro municipios de la provincia de Ceará, durante tres meses consecutivos. Resultados: Las observaciones muestran una alta tasa de no conformidades antes, durante y después del período. Entre los factores de riesgo de contaminación se encuentran fallas en la higiene de los utensilios, en las prácticas higiénicas de los manipuladores, además de la presencia de vectores mecánicos contaminantes. Conclusión: La comercialización de pescado en los mercados públicos indica condiciones que ofrecen riesgos de contaminación para el pescado y pueden no ser seguras para la salud del consumidor. Dichos hallazgos pueden presentar a las autoridades sanitarias de la provincia de Ceará un panorama de la realidad de la comercialización del pescado tanto en fechas conmemorativas como durante todo el año y, así, estimular la realización de capacitaciones con gestores y comerciantes, así como la reestructuración higiénico-sanitaria. mercados públicos destinados a la seguridad alimentaria de la población.

Palabras clave: Carne, Comercializacíon de productos, Higiene alimentaria.

\section{INTRODUÇÃO}

As Doenças Transmitidas por Alimentos (DTAs), são um grave problema de saúde pública que podem manifestar na forma de infecções, intoxicações e toxinfecções alimentares. As DTAs têm como fatores causais manipulação, preparação, conservação e matéria-prima de qualidade inadequada. Dentre os alimentos envolvidos em surtos de DTA, os produtos de origem animal se destacam como as principais fontes de infecção, dentre eles o pescado (ALMEIDA JC, et al., 2013).

Pescado são os animais aquáticos que vivem na água salgada ou doce e são capturados para que sua carne seja utilizada para fins alimentares. Dentre eles podemos citar os peixes. O pescado é considerado um dos alimentos mais saudáveis e nutritivos, sendo uma as principais fontes de nutrientes e consumo na alimentação humana. Entretanto, são altamente perecíveis e podem ser veículos de microrganismos patogênicos como Escherichia coli, Enterococcus faecalis, Vibrio cholerae e V. vulnificus (ORNELAS LH, 2006; SARTORI AGO e AMANCIO RD, 2012; SILVA IA, et al., 2012; EMBRAPA, 2013; ALMEIDA JC, et al., 2013; EVANGELISTA-BARRETO NS, et al., 2017).

A região Nordeste do Brasil consome pescado acima da média nacional. Este consumo aumenta durante o período comemorativo da Semana Santa. Sendo comum a aquisição do pescado em mercados públicos (SOARES KMP e GONÇALVES AA, 2012; COSTA TV, et al., 2013; LIMA KF, et al., 2016; REYES PR e ESPINOZA IM, 2018).

Os mercados públicos são uma alternativa de aquisição de gêneros alimentícios devido a variedade dos produtos, localizados próximo a residências, preços, ofertas, posssibilidade de negociação e atenção recebida. No entanto, muitos apresentam algumas desvantagens relacionadas a desordem e a falta de higiene (SARTORI AGO e AMANCIO RD, 2012; FREITAS, MR e OLIVEIRA, CR , 2017; REYES PR e ESPINOZA IM, 2018).

A comercialização de pescado em mercados públicos costuma não respeitar a as boas práticas de manipulação, armazenamento e comercialização de alimentos que podem comprometer a qualidade dos produtos e colocar em risco a saúde do consumidor, necessitando fiscalização ao longo de toda sua cadeia produtiva.

Desta forma, muitos mercados públicos brasileiros necessitam de intervenção em sua infraestrutura por apresentarem graves problemas higiênico-sanitários que comprometem as condições de comercialização para alimentos perecíveis, como o pescado, colocando em risco a saúde do consumidor (SANTOS AT, et al., 2014, GIRÃO MVD, et al., 2015; SOUZA, et al., 2016; SILVA RX, et al., 2016 EVANGELISTA-BARRETO NS, et al., 2017; SILVA-JUNIOR ACS, et al., 2017; SOUZA TM, ATAYDE HM., 2017). 
Desta forma, o objetivo desta pesquisa foi avaliar as condições higiênico-sanitárias durante a comercialização de pescado em mercados públicos do estado do Ceará, a fim de identificar as condições estruturais e hábitos adotados pelos manipuladores antes, durante e após o período da Semana Santa.

\section{MÉTODOS}

Estudo do tipo exploratório, investigativo, descritivo de campo, transversal e observacional, com abordagem qualitativa e quantitativa. Partindo as seguintes indagações norteadoras: "Como são realizadas as boas práticas de manipulação, conservação e exposição do pescado em mercados públicos do estado do Ceará, Brasil? Existe mudanças de hábitos higiênico-sanitários durante a Semana Santa quando comparados com outros meses do ano?

O Sistema Único de Saúde (SUS) possui a diretriz da regionalização que orienta o processo de descentralização das ações e serviços de saúde e os processos de negociação e pactuação entre os gestores. A regionalização da Saúde do Ceará está representada por 22 regiões, onde se estrutura o Sistema Estadual de Saúde.

Cada região tem um órgão de representação da Secretaria Estadual da Saúde, denominada Coordenadoria Regional de Saúde (CRES) com a finalidade de integrar a organização, o planejamento e a execução de ações e serviços de saúde. Dentre as diretrizes de organização das regiões está a organização da atenção primária municipal, incluindo a vigilância sanitária (CEARÁ, 2019). Desta forma, a amostra do presente estudo é composta por quatro municípios do estado do Ceará, sendo um da $6^{\underline{a}}$ CRES, dois da $11^{\text {a }}$ CRES e um município da 13ª CRES (Figura 1).

Figura 1 - Mapa do estado do Ceará indicando as Coordenadorias Regionais de Saúde (CRES). Em destaque as CRES $6^{\underline{a}}, 11^{\text {a }}$ e $13^{\underline{a}}$ que tiveram municípios inspecionados.

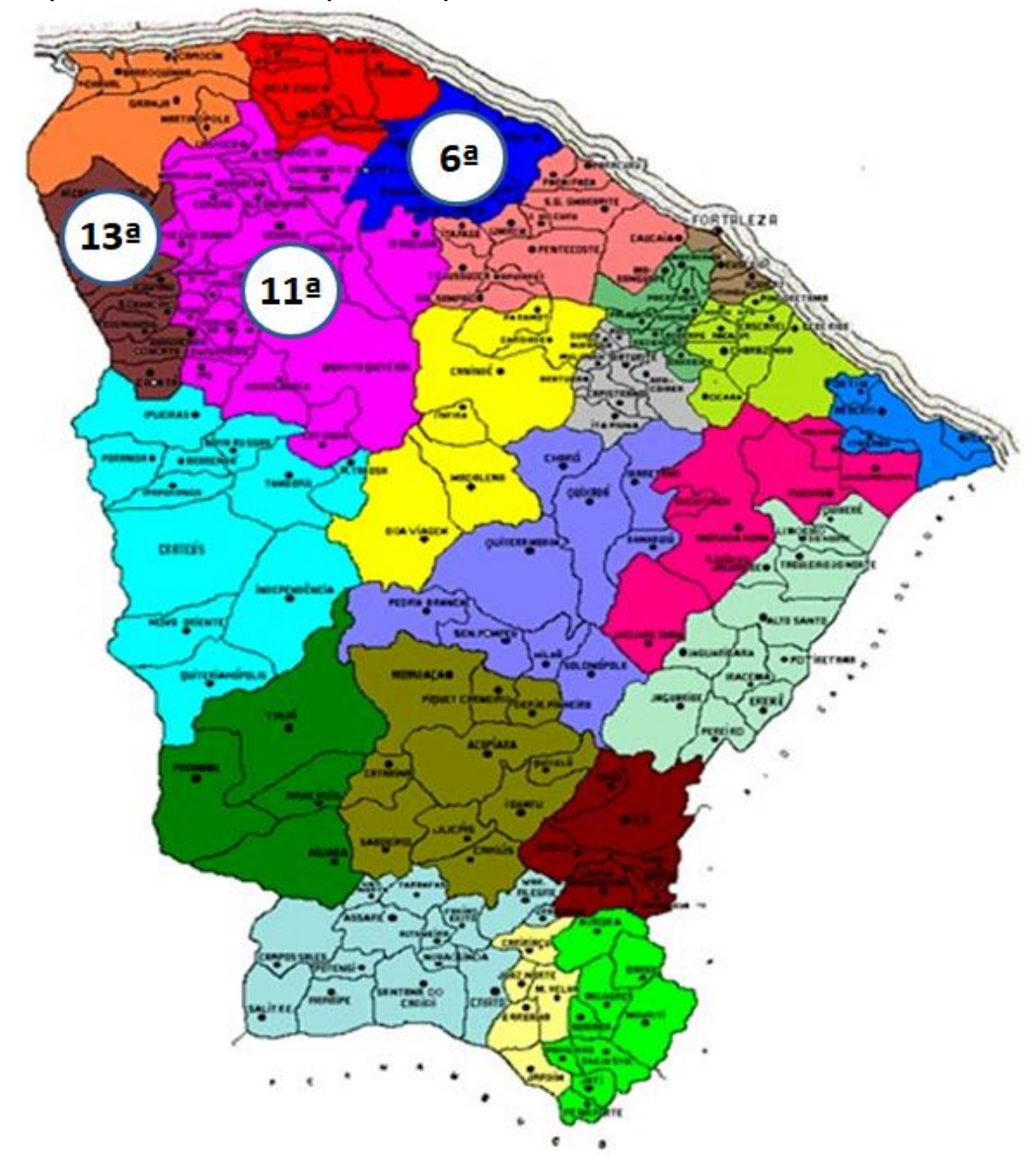

Fonte: Teixeira SKCA, et al., 2020. 
A amostragem foi do tipo intencional definida por conveniência para a coleta de dados. A amostra foi composta por quatro mercados públicos municipais estruturados para vender além de pescado, outros produtos cárneos, cereais e hortaliças. Para preservar o anonimato dos municípios, seus nomes foram substituídos pelo código "M", seguido de um número arábico de um a quatro.

Foram utilizados como critérios de inclusão os mercados públicos municipais que comercializam pescado do tipo peixes, em estabelecimentos comerciais físicos do tipo barraca, box ou loja, nos quais ocorre circulação livre de pessoas e clientes. Foram excluídas as feiras livres, mercados ou comércios privados e comerciantes itinerantes ou ambulantes.

A coleta de dados foi realizada no período de março, abril e maio de 2019. O período definido para a coleta de dados buscou os meses referentes ao período antes, durante e após o período comemorativo da semana santa. Os pesquisadores realizaram três inspeções "in loco" para a coleta dos dados ocorrendo das 7:00 às 10:00 horas, principal horário de comercialização nos mercados. As inspeções foram realizadas por profissionais treinados para o preenchimento do checklist e experientes da área de alimentação e nutrição.

A coleta de dados foi por meio de observações não participantes, utilizando como instrumentos a aplicação da ficha de verificação do tipo checklist das boas práticas nos moldes recomendados pela RDC no da Agência Nacional de Vigilância Sanitária, que dispõe sobre o Regulamento Técnico de Boas Práticas para Serviços de Alimentação. Tendo como finalidade identificar as Práticas realizadas nos mercados públicos.

As recomendações da RDC 216 (BRASIL, 2004) foram adaptadas para se adequarem a inspeção nos estabelecimentos de comercialização de peixes. O checklist era composto de total de 75 itens organizados em 10 blocos. O bloco 1 contempla trinta e um critérios sobre os aspectos de Edificação, instalações, equipamentos, móveis e utensílios. O bloco 2 contempla nove critérios sobre Higienização das instalações, equipamentos, móveis e utensílios. O bloco 3 contempla dois critérios sobre o controle integrado de vetores e pragas urbanas. O bloco 4 contempla dois critérios sobre Abastecimento de água. O bloco 5 contempla quatro critérios sobre o Manejo dos resíduos. O bloco 6 contempla quatorze critérios sobre os Manipuladores. O bloco 7 contempla quatro critérios sobre a Matéria-prima. O bloco 8 contempla critérios sobre a preparação de alimentos tendo como critério de análise a forma de exposição do alimento à venda. O bloco 9 contempla quatro critérios sobre o armazenamento e transporte do alimento. O bloco 10 contempla quatro critérios sobre a exposição do alimento. O critério para classificação dos estabelecimentos foi baseado na adequação de cada item em relação ao roteiro submetido, seguindo os parâmetros de conformidade $(C)$ ou de não conformidade (NC).

A classificação do índice de conformidade seguiu as orientações da RDC 275 ( BRASIL, 2002), onde os estabelecimentos avaliados através de checklist podem ser classificados em três grupos quanto ao atendimento dos itens: Grupo 1 de 76 a 100\% de atendimento dos itens, estabelecimentos com instalações, equipamentos, processo e controles bem estruturados e organizados; Grupo 2 de 51 a $75 \%$ de atendimento dos itens, estabelecimentos que ainda necessitam de melhorias quanto as instalações, dependendo do que necessita ser melhorado, os alimentos comercializados neste tipo de estabelecimento podem não ser seguros à saúde do consumidor; Grupo 3 de 0 a 50\% de atendimento dos itens, os alimentos comercializados neste tipo de estabelecimento podem não ser seguros à saúde do consumidor. Cada mercado serviu de próprio controle para as observações aos longos dos meses.

Para a tabulação dos dados, formulação das tabelas e categorias a serem analisados, utilizou-se o programa Microsoft Office Excel $2010 \AA$. Após a coleta, os dados foram tabulados e as análises descritivas dos dados foram realizadas, utilizando as medidas de razão e proporção sendo considerados para o cálculo o número do total de itens de cada grupo e o número de itens em conformidade.

\section{RESULTADOS}

Os dados coletados através do roteiro observacional por meio de checklist atestaram ausência do cumprimento às Boas Práticas. Considerando o total de itens aplicáveis os mercados públicos municipais tiveram uma média geral de $11,8 \%$ de atendimento dos itens, sendo classificados no grupo 3 da RDC 275, o que indica que os alimentos comercializados neste tipo de estabelecimento podem não ser seguros à saúde do consumidor. 
Todos os blocos analisados mostraram situação higiênico-sanitária crítica. Sendo que o bloco que apresentou maior percentual de adequação foi o Abastecimento de água. O maior percentual de inadequação, os blocos Controle integrado de vetores e pragas urbanas; Matérias-primas; Preparação de alimentos; e Armazenamento e transporte do alimento (Tabela 1).

Os resultados de cada bloco foram semelhantes em todos os estabelecimentos, não houve variação de condutas antes, durante ou após o período da Semana Santa. Entretanto, com o aumento do fluxo de clientes durante o período da Semana Santa as boas práticas passaram a ser frequentemente negligenciadas.

Tabela 1 - Percentual de conformidade das boas práticas para serviços de alimentação dos mercados públicos municipais de comercialização de peixes do estado do Ceará, Brasil.

\begin{tabular}{|c|c|c|c|c|c|c|}
\hline Blocos segundo DRC 216 & M1 & M2 & M3 & M4 & $\begin{array}{l}\text { Média } \\
\text { do } \\
\text { bloco }\end{array}$ & $\begin{array}{c}\text { Conformidade } \\
\text { do bloco } \\
\text { segundo RDC } \\
275\end{array}$ \\
\hline $\begin{array}{l}\text { 1. Edificação, instalações, } \\
\text { equipamentos, móveis e utensílios }\end{array}$ & $19,3 \%$ & $12,9 \%$ & $9,6 \%$ & $22,5 \%$ & $16 \%$ & $\begin{array}{l}\text { Grupo } 3 \\
\text { Ruim }\end{array}$ \\
\hline $\begin{array}{l}\text { 2. Higienização das instalações, } \\
\text { equipamentos, móveis e utensílios }\end{array}$ & $22,2 \%$ & $0 \%$ & $11,1 \%$ & $22,2 \%$ & $13,8 \%$ & $\begin{array}{l}\text { Grupo } 3 \\
\text { Ruim }\end{array}$ \\
\hline $\begin{array}{l}\text { 3. Controle integrado de vetores e } \\
\text { pragas urbanas }\end{array}$ & $0 \%$ & $0 \%$ & $0 \%$ & $0 \%$ & $0 \%$ & $\begin{array}{l}\text { Grupo } 3 \\
\text { Ruim }\end{array}$ \\
\hline 4. Abastecimento de água & $50 \%$ & $25 \%$ & $0 \%$ & $0 \%$ & $18,7 \%$ & $\begin{array}{l}\text { Grupo } 3 \\
\text { Ruim }\end{array}$ \\
\hline 5. Manejo dos resíduos & $50 \%$ & $0 \%$ & $25 \%$ & $0 \%$ & $18,7 \%$ & $\begin{array}{l}\text { Grupo } 3 \\
\text { Ruim }\end{array}$ \\
\hline 6. Manipuladores & $7,1 \%$ & $21,4 \%$ & $14,2 \%$ & $14,2 \%$ & $14,2 \%$ & $\begin{array}{l}\text { Grupo } 3 \\
\text { Ruim }\end{array}$ \\
\hline 7. Matérias- prima & $0 \%$ & $0 \%$ & $0 \%$ & $0 \%$ & $0 \%$ & $\begin{array}{l}\text { Grupo } 3 \\
\text { Ruim }\end{array}$ \\
\hline 8. Preparação de alimentos & $0 \%$ & $0 \%$ & $0 \%$ & $0 \%$ & $0 \%$ & $\begin{array}{l}\text { Grupo } 3 \\
\text { Ruim }\end{array}$ \\
\hline $\begin{array}{l}\text { 9. Armazenamento e transporte do } \\
\text { alimento }\end{array}$ & $0 \%$ & $0 \%$ & $0 \%$ & $0 \%$ & $0 \%$ & $\begin{array}{l}\text { Grupo } 3 \\
\text { Ruim }\end{array}$ \\
\hline 10. Exposição do alimento & $25 \%$ & $25 \%$ & $0 \%$ & $25 \%$ & $18,7 \%$ & $\begin{array}{l}\text { Grupo } 3 \\
\text { Ruim }\end{array}$ \\
\hline Média de adequação por mercado & $17,3 \%$ & $10,9 \%$ & $5,9 \%$ & $13,3 \%$ & $\begin{array}{l}\text { Média } \\
\text { Geral }\end{array}$ & $11,8 \%$ \\
\hline $\begin{array}{l}\text { Conformidade do mercado } \\
\text { RDC } 275\end{array}$ & $\begin{array}{l}\text { Grupo } 3 \\
\text { Ruim }\end{array}$ & $\begin{array}{c}\text { Grupo } 3 \\
\text { Ruim }\end{array}$ & $\begin{array}{l}\text { Grupo } 3 \\
\text { Ruim }\end{array}$ & $\begin{array}{l}\text { Grupo } \\
3 \text { Ruim }\end{array}$ & --- & --- \\
\hline
\end{tabular}

Fonte: Teixeira SKCA, et al., 2020.

No bloco Edificação, instalações, equipamentos, móveis e utensílios, condições de não conformidade mais facilmente identificáveis foram a higienização indevida dos utensílios. Nos boxes a pia era utilizada para todas as atividades favorecendo a contaminações cruzadas.

Os detergentes comercialmente destinados a lavagem de pratos ou roupas são usados para a higienização das mãos. É perceptível falta de higiene pessoal e dos materiais usados no processo de manipulação.

No bloco Higienização das instalações, equipamentos, móveis e utensílios, foi evidenciado que as não conformidades superam as conformidades. Ações preventivas adotadas em um mercado são diferentes das adotadas em outros.

Foram facilmente observadas situações em que a área de manipulação higienizada com panos de algodão compartilhado para a mesa de corte, balcão, mãos e até mesmo afastar pragas dos alimentos. Os produtos saneantes armazenados em locais inadequados, muitas vezes na parte inferior ou sobre o balcão e pias do box de comercialização. 
Foi verificada em todas as unidades o não uso de uniformes pelos funcionários responsáveis pela higienização das instalações. Não eram apropriados para a função e diferenciados daqueles utilizados na manipulação dos alimentos. Em alguns casos, o comerciante acumulava as funções de manipulador e de limpeza do ambiente.

No bloco Controle integrado de vetores e pragas urbanas, todos os mercados inspecionados estão em total desacordo. As inadequações foram facilmente visualizadas como a presença de vetores e pragas urbanas sobrevoando os alimentos e não foi verificada certificado de dedetização. Sendo necessária a adoção de práticas que evitem a atração, o abrigo, o acesso e ou proliferação de vetores e pragas urbanas.

No bloco Abastecimento de água, os resultados variaram de total desacordo a desacordo parcial. Três mercados o abastecimento ocorria por água encanada e por meio de caixa d'água. Entretanto, em um foi observado a presença de água armazenada em recipientes sobre pias e piso dos boxes sendo utilizada para a higienização da estrutura física, manipuladores e alimentos, sugerindo ser um hábito para compensar eventual corte no abastecimento de água. Em não existia abastecimento de água.

No bloco Manejo dos resíduos foi possível visualizar o trânsito de clientes, recepção de mercadorias e resíduos pelo mesmo acesso. Inexistência de coletores de resíduos nas áreas de circulação do mercado. Alguns manipuladores descartam os resíduos do pescado em sacos plásticos no chão do box de comercialização.

No bloco Manipuladores, as condições de não conformidade mais facilmente identificáveis foram que os comerciantes falavam desnecessariamente durante o desempenho das atividades, a não higienização das mãos após tocarem o próprio corpo, tocar em alimentos crus, sacarias, dinheiro, resíduos e após utilizar materiais ou utensílios de limpeza. Bem como o não uso de EPIs, a falta de asseio pessoal, uso de barba e cabelos expostos e zelo pela limpeza das vestimentas.

No bloco Matéria-prima, não foi identificada a supervisão da chegada das matérias primas e quando expostos à venda o pescado fica sujeito a vetores, ao contato direto de manipuladores, clientes, sem aparato de proteção.

No bloco Preparação de alimentos, foi evidenciado que os peixes ficam em sua maioria exposto a temperatura ambiente sem controle de tempo e temperatura.

No bloco Armazenamento e transporte do alimento, foi evidenciado que o transporte dos peixes era feito em motos, carroças e caminhões abertos, acondicionados em caixas plásticas sem refrigeração ou vedação apropriada.

No bloco Exposição do alimento, foi evidenciado que o peixe comercializado fica exposto sem proteção, estando sujeito ao contato com vetores, sujidades e manuseio dos consumidores.

\section{DISCUSSÃO}

Os mercados públicos pesquisados apresentam várias inconformidades em relação aos critérios da RDC 216. Andrade CMA, et al. (2017) inspecionaram o comércio de pescado na mesma região do presente estudo e identificaram total não conformidade das boas práticas para serviços de alimentação.

Os resultados de Souza ERS, et al. (2016) corroboram com o presente estudo, onde afirmam existir graves problemas higiênico-sanitários nos mercados públicos municipais que comprometem a qualidade dos produtos e colocam em risco a saúde do consumidor por apresentarem não conformidades relacionadas à estrutura física, quantidade suficiente ou ausência de coletores de resíduos próximos a área de manipulação de alimentos.

A falta de infraestrutura dos mercados públicos proporciona o comércio inadequado do pescado sobre balcões de madeira ou de alvenaria revestido com azulejo em condições inadequadas. Alguns mercados públicos necessitam de intervenção em sua infraestrutura, não apresentando condições de comercialização para alimentos perecíveis, como o pescado (SILVA RX, et al., 2016; EVANGELISTA-BARRETO NS, et al., 2017). 
O cumprimento da RDC 216 (BRASIL, 2004) A é de extrema relevância para a promoção da saúde dos consumidores de peixes adquiridos nestes estabelecimentos. De acordo com o panorama sanitário identificados, os mercados públicos municipais devem ser tratados como prioridade das estratégias institucionais de intervenção. Considera-se que uma revitalização e uma adequada administração pode promover mudanças positivas nos padrões higiênico-sanitários comumente encontrados na região estudada.

As condições também são observadas em alguns outros mercados do Brasil onde se observa que a higiene no manuseio do pescado é precária. Os equipamentos e utensílios também apresentam estado depreciado de conservação. Condições propícias para o crescimento de microrganismos patogênicos (EVANGELISTA-BARRETO NS, et al., 2017, SILVA-JUNIOR ACS, et al. 2017; SOUZA TM e ATAYDE HM, 2017).

Entretanto, Santos EHB, et al. (2016) encontraram uma realidade diferente à do presente estudo. $\mathrm{O}$ dimensionamento das edificações e das instalações físicas era compatível com todas as operações realizadas nos boxes condizentes para a manipulação do pescado e operações de manutenção, limpeza e desinfecção. É oportuno enfatizar que os equipamentos podem ser veículos importantes de contaminações cruzadas, necessitando, assim, serem de fácil limpeza e desinfecção, facilmente desmontáveis e montáveis. Devem ser adotados utensílios que permitiam uma fácil higienização, e armazenagem correta em local apropriado, de forma organizada e protegidos contra a contaminação.

Embora alguns mercados possuam abastecimento de água, a qualidade da água de abastecimento pode se duvidosa. Para verificar a real qualidade da água é necessário um controle por parte das autoridades sanitárias (MOUCHREK NA e CARVALHO ECC, 2016; PORCY C et al., 2020).

Souza ERS, et al. (2016) e Evangelista-Barreto NS, et al. (2017) realizaram estudo em mercados públicos da região nordeste do Brasil e também verificaram condições impróprias quanto o abastecimento de água. Os boxes eram abastecidos com água oriunda de poço artesiano, armazenada em caixa d'água sem tampa, com número de torneiras insuficientes, sendo comum a utilização de baldes para lavagem de mãos, utensílios e bancadas. Em alguns boxes a água armazenada em um recipiente era utilizada para a lavagem das mãos e pescado, simultaneamente.

A higiene dos manipuladores é de extrema importância para garantir a segurança alimentar, sendo a lavagem das mãos uma etapa básica. Pois os manipuladores de alimentos podem ser uma fonte de transmissão de doenças infecciosas e parasitárias, sendo necessária a avaliação periódica da saúde dos manipuladores de alimentos (CUNHA LF e AMICHI KR, 2014; SILVA RX, et al., 2016; EVANGELISTABARRETO NS, et al., 2017; SOUSA FA et al., 2017).

A presença de pragas ou vetores ambiente de comercialização de alimentos indica riscos de transmissão de patógenos. A sua ocorrência deve servir de alerta aos administradores para o cumprimento das normas sanitárias (SCHWINGEL I, et al., 2016).

O manejo correto dos resíduos pode minimizar a presença de vetores. O que se observa em mercados de peixe é um número insuficiente ou em condições de conservação precárias. Como também, a frequência da coleta é insuficiente promovendo o acúmulo de escamas e vísceras sobre as bancadas onde se coloca o peixe a venda. Estas práticas provocam odores indesejáveis, atraem animais como cães, gatos e até mesmo urubus, que circulam entre os clientes (SILVA RX, et al., 2016, SANTOS EHB, et al., 2016, SILVA-JUNIOR ACS, et al. 2017; SOUZA TM e ATAYDE HM, 2017).

A exposição prolongada dos alimentos a temperaturas tropicais pode alterar as características sensoriais e nutricionais dos alimentos, além de expô-los a contaminação microbiológica, devido à inexistência do controle de temperatura (EVANGELISTA-BARRETO NS, et al., 2017, SOUZA TM e ATAYDE HM, 2017).

Rotineiramente é possível observar em mercados públicos peixes que apresentam cor opaca, escamas desprendendo-se com facilidade, olhos fora da órbita e vísceras à amostra expostos à venda juntamente com peixes que aparentemente estão em condições adequadas, facilitando a contaminação cruzada (MACEDO DS, et al., 2015; SOUZA ERS, et al., 2016, SILVA-JUNIOR ACS, et al. 2017). 
As matérias-primas devem ser transportadas e acondicionados com identificação em local limpo e organizado, que garanta a integridade e os proteja contra contaminantes. Conservar o alimento a ser comercializado de forma refrigerada é uma importante ferramenta no controle de microrganismos patogênicos, pois alimentos comercializados refrigerados apresentam um índice menor de contaminação (BRASIL, 2004; DIAS JN, et al. 2015; SILVA-JUNIOR ACS, et al. 2017, SOUZA TM e ATAYDE HM, 2017; DRUZIAN MM e BONI BR, 2016).

Melo FEB, et al. (2018) sintetizam as nossas observações, constatando inadequações sanitárias relacionadas ao uso não adequado de EPI's, higienização incorreta das mãos e animais circulando entre os boxes. Esses fatores expõem comprometem a qualidade e a integridade dos produtos cárneos e, por consequência, aumentado os riscos de DTAs à população. As condições higiênico-sanitárias dos estabelecimentos comerciais de pescado indicam que estes estabelecimentos necessitam de melhorias em sua gestão.

Não podemos afirmar em nosso estudo que os peixes comercializados estão contaminados, mas quando as condutas higiênico-sanitárias não são adotadas contribuem para a perda da qualidade e início de deterioração do pescado. Desta forma, as condições da estrutura física, higiene do ambiente, dos utensílios, manipulação, transporte e exposição à venda identificadas são propícias para a contaminação.

Este trabalho apresenta relevância para a comunidade científica, pois mesmo trazendo resultados já discutidos em pesquisas anteriores, compila em um mesmo manuscrito o perfil higiênico-sanitário de diversos mercados públicos do estado do Ceará, apresentando uma realidade preocupante da comercialização de peixes nos mercados públicos avaliados. As inadequacies higienico-sanitárias recorretes são mais que suficientes para que os gestores tomem medidas corretivas.

\section{CONCLUSÃO}

Os mercados públicos analisados apresentam não conformidades higiênico-sanitárias em todos os critérios analisados, mas principalmente na higienização de utensílios, nas práticas de higiene dos manipuladores, além da presença de vetores mecânicos contaminantes. Condições que oferecem riscos de contaminação ao pescado. As não conformidades foram identificadas nos três períodos analisados, antes, durante e após o período a Semana Santa. Tais achados apresentam um panorama da realidade da comercialização de pescado ao longo do ano e, assim, podem servir para orientar na gestão dos mercados públicos visando à segurança alimentar da população. Tais achados podem contribuir para traçar um perfil higiênico-sanitário dos mercados públicos municipais do Brasil.

\section{REFERÊNCIAS}

1. ALMEIDA JV, et al. Perfil epidemiológico de casos de surtos de doenças transmitidas por alimentos ocorridos no Paraná, Brasil. Semina: Ciências Biológicas e da Saúde, Londrina, 2013;34(1):97-106.

2. ANDRADE CMA, et al. Gestão ecológica e higiênico-sanitária do comércio do Caranguejo-uçá (Ucides cordatus) no município de Sobral -CE. Revista Gestão e Sustentabilidade Ambiental, 2017; 6(2):171-183.

3. ANDRADE GF, BARROS, DB. Bioindicadores Microbiológicos para Indicação de poluição Fecal. Revista Acervo Saúde, 2010; 7(34): 1-7.

4. Brasil. Ministério da Saúde. Secretaria de Vigilância Sanitária. Agência Nacional de Vigilância Sanitária. Resolução RDC n. 27521 de outubro de 2002. Dispõe sobre o regulamento técnico de procedimentos operacionais padronizados aplicados aos estabelecimentos produtores/industrializadores de alimentos e a lista de verificação das Boas Práticas de Fabricação em Estabelecimentos Produtores/Industrializadores de Alimentos. Diário Oficial da República Federativa do Brasil. Disponível em: https://www.gov.br/anvisa/pt-br. Acesso em: 03 out. 2020.

5. Brasil. Ministério da Saúde. Secretaria de Vigilância Sanitária. Agência Nacional de Vigilância Sanitária. Resolução RDC n. 21615 de setembro de 2004. Dispõe sobre regulamento técnico de boas práticas para serviços de alimentação. Diário Oficial da República Federativa do Brasil. Disponível em: https://www.gov.br/anvisa/pt-br. Acesso em: 03 out. 2020.

6. CEARÁ, Secretaria da Saúde do Estado do Ceará- SESA. Disponível em: http://www.saude.pr.gov.br/modules/conteudo/conteudo.php?conteudo=2796. Acesso em 02. Jul. 2019.

7. COSTA TV, et al. Aspectos do consumo e comércio de pescado em Parintins. Boletim do Instituto de Pesca, 2013 ; 39(1): 63-75. 
8. CUNHA LF, Amichi KR. Relação entre a ocorrência de enteroparasitoses e práticas de higiene de manipuladores de alimentos: revisão da literatura. Revista Saúde e Pesquisa, 2014; 7(1): 147-157.

9. DIAS JN, et al. Avaliação das condições higiênico-sanitárias de leite cru e queijo coalho comercializados em mercados públicos no norte do Piauí. Revista Saúde e Pesquisa, 2015; 8(2): 277-284.

10. DRUZIAN MM, BONI BR. Matérias-primas e transporte de alimentos preparados: condições higiênicos-sanitárias em uma unidade de alimentação e nutrição hospitalar. Higiene Alimentar, 2016; 30(254/255): 66-69.

11. EMBRAPA. Influência da Nutrição sobre a qualidade do pescado: Especial referência aos ácidos graxos. Corumbá: Embrapa Documentos; 2013; 20 p.

12. EVANGELISTA-BARRETO NS, et al. Condições higiênicos sanitárias e grau de frescor do pescado comercializado no mercado de peixe em Cachoeira, Bahia. Revista Brasileira de Higiene e Sanidade Animal; 2017; $11(1): 60-74$.

13. FREITAS, MR, OLIVEIRA, CR. Era uma casa muito engraçada, não tinha teto, não tinha nada! As representações sociais do mercado municipal de Uberlândia. Revista de Administração IMED, 2017; 7(1): 137-157.

14. GIRÃO MVD, et al. Condições higiênico-sanitárias na comercialização de pescados em Sobral - CE. Vigilância sanitária em debate, 2015; 3(4): 136-140.

15. LIMA KF, et al. A comercialização do pescado no município de Aantarém, Pará. Revista Brasileira de Engenharia de Pesca, 2016; 9(2): 1-9.

16. MELO FEB, et al. Condições higiênico-sanitárias para comercialização de carnes em mercados públicos do recifepe. Journal of Health Connections, 2018; 3(2): 1-13.

17. MOUCHREK NA, CARVALHO ECC. Qualidade da água em serviços de alimentação de um bairro da zona rural de São Luís, Maranhão, Brasil. Revista Brasileira de Pesquisa em Saúde, 2016; 18(3): 130-136.

18. ORNELAS LH. Técnica Dietética: seleção e preparo de alimentos. São Paulo: Atheneu. 8 eds. 2006,296 p.

19. PORCY C, et al. Avaliação microbiológica da água de consumo de casas localizadas em área alagada em um município do estado Amapá. Revista Acervo Saúde, 2020; 12(4): 1-9.

20. REYES PR, ESPINOZA IM. Satisfacción del cliente con la actividad comercial de los mercados públicos de la Heroica Ciudad de Huajuapan de León, 2018; 7(13): 95-113.

21. SANTOS AT, et al. Análise microbiológica e condições higiênicas sanitárias com propriedades da carne bovina vendida em mercados públicos de Teresina - PI. R. Interdisciplinar, 2014; 7(1): 25-33.

22. SANTOS EHB, et al. Avaliação das Condições Higiênico-Sanitárias no Comércio de Pescados em um Mercado do Peixe. J Health Sci, 2016; 18(3): 151-8.

23. SARTORI AGO, AMANCIO RD. Pescado: importância nutricional e consumo no Brasil. Segurança Alimentar e Nutricional, 2012; 19(2): 83-93.

24. SCHWINGEL I, et al. Formigas (hymenoptera: formicidae) em centros de saúde da família de Chapecó, SC. Revista Brasileira de Geografia Médica e da Saúde, 2016; 12(23): 111-121.

25. SILVA IA, et al. Perfil de consumidores do pescado comercializado em mercados do município de São Luís, Maranhão, Brasil. Cadernos de pesquisa (São Luis), 2012; 19(1): 59-63.

26. SILVA-JUNIOR ACS, et al. Avaliação da condição higiênico-sanitária na comercialização de pescado da feira do produtor rural do Buritizal, Macapá-Amapá. LifeStyle Journal, 2017; 4(1): 71-81.

27. SOARES KMP, GONÇALVES AA. Qualidade e segurança do pescado. 2012. Revista do Instituto Adolfo Lutz, 2012; 71(1): 1-10.

28. SOUSA FA, et al. Caracterização higiênico-sanitária e tecnológica dos pescadores e da tilápia do nilo (Oreochromis niloticus) comercializada no mercado municipal de Salinas-MG. Revista Brasileira de Ciência Veterinária, 2017; 24(4): 197-200.

29. SOUZA ERS, et al. Boas Práticas de Manipulação de Pescados em Mercados Públicos do Recife-PE. Revista eletrônica Estácio Recife, 2016; 1(1): 1-10.

30. SOUZA TM, ATAYDE HM. Educação higiênico-sanitária dos feirantes do Mercadão 2000 e Feira do Pescado em Santarém-PA. Revista Brasileira de Extensão Universitária, 2017; 8(3): 127-134. 